needed because of continued bleeding correct preoperative diagnosis of the syndrome could greatly reduce the length of the surgical procedure for a condition which can be difficult to identify at laparotomy. When bleeding stops spontaneously the emphasis of medical advice can be correctly placed on reduction of alcohol consumption (where appropriate) rather than on the unnecessary prescription of antacids or anticholingergics. Finally, a selective policy of treatment with vasopressin (Dill et al., 1972) requires accurate identification of the bleeding point.

\section{References}

Atkinson, M., et al. (1961). Gut, 2, 1.
Cotton, P. B., Rosenberg, M. T., Waldram, R. P. L., and Axon, A. T. R. (1973). British Medical fournal, 2, 505.

Cremer, M., Gulbis, A., Peeters, J. P., and Desneux, J. J. (1973). In Urgent Endoscopy of Digestive and Abdominal Diseases, ed. Z. Maratka, p. 132. Basel, Karger.
Dagradi, A. E., Broderick, J. T., Juler, G., Wolinsky, S., and Stempien, S. J. (1966). American fournal of Digestive Diseases, 11, 710.

Delumeau, G., Perrin, D., de Lisle, L. R., Veyrac, Y., and Miniconi, P. (1972). Annales de Gastroénterologie et d'Hépatologie, 8, 329.

Dill, J. E., Wells, R. F., and Levy, M. (1972). Gastrointestinal Endoscopy, $18,157$.

Dobbins, W. O. (1963). Gastroenterology, 44, 689.

Dudlev, H. A. F., St. John, D. J. B., and Masterton, J. P. (1973). Proceedings of the 46th General Scientific Meeting of the Royal Australasian College

Freeark, R. J, Norcross, W. J Bak ., Norcross, . J., Baker, R. J., and Strohl, E. L. (1964) Archives of Surgery, 88, 882.

Holmes, K. D. (1966). Annals of Surgery, 164, 810.

Jones, F. A. (1969). British Medical fournal, 2, 267

Katz, D., Freud, M., and McKinnon, W. M. P. (1965). American fournal of Digestive Diseases, 10, 314.

Mallory, G. K., and Weiss, S. (1929). American fournal of Medical Sciences, 178, 506.

Morrissev, J. F. (1972). Gastroenterology, 62, 1241.

Palmer, E. D. (1970). In Upper Gastrointestinal Haemorrhage. Springfield Illinois, Thomas.

Pitcher, J. L. (1972). Gastrointestinal Endoscopy, 18, 122.

Weaver, D. H., Maxwell, J. G., and Castleton, K. B. (1969). American Fournal of Surgery, 118, 887.

Wells, R. F. (1967). Southern Medical Fournal, 60, 1197.

\title{
Tuberculous Lymphadenitis
}

\section{P. B. ILES, P. A. EMERSON}

British Medical fournal, 1974, 1, 143-145

\section{Summary}

A total of 43 episodes of tuberculosis lymphadenitis were treated in 32 adult patients. In 12 instances the affected lymph node was excised without any chemotherapy; there were 10 relapses. The treatment was local excision of the affected lymph nodes together with antituberculosis chemotherapy with at least two drugs in 30 instances; there were no relapses following such therapy.

Presumably patients with tuberculosis lymphadenitis are still sometimes treated with surgery alone because that was at one time the orthodox line of surgical teaching. Such a view is out of date: these patients should always be given antituberculosis therapy in addition to any surgical measures.

\section{Introduction}

While reviewing the results of treatment of adult patients with various forms of tuberculosis in Westminster Hospital during the period January 1965 to May 1973 we found that they were much less satisfactory in cases of tuberculous lymhadenitis than in those of other types of tuberculosis. This was a matter for concern and we decided to study these cases more closely. This paper reports our findings.

\section{Patients and Diagnosis}

Of the 32 patients with tuberculous lymphadenitis treated during the eight-year period 20 were females aged 15 to 76 years and 12 were males aged 15 to 50 years; 14 were from abroad. Altogether 25 patients were referred by general practitioners and five by other hospitals; two developed their tuberculous lymphadenopathy while they were already on

Westminster Hospital, London SW1P 2AP

P. B. ILES, M.B., M.R.C.P., Registrar in Medicine

P. A. EMERSON, M.D., F.R.C.P., Consultant Physician chemotherapy for pulmonary tuberculosis. The follow-up details of those no longer attending the hospital were obtained from the patients and their medical praotitioners.

Twenty-seven patients had no evidence of other organ involvement; in three there was also active pulmonary tuberculosis and in one there was tuberculous peritonitis; the other patient also had miliary tuberculosis with pulmonary and meningeal involvement.

In 30 patients the diagnosis of tuberculous lymphadenitis was confirmed by excision biopsy either before or after reference to Westminster Hospital. In the other two the diagnosis was made by examination of pus obtained by needle aspiration without biopsy. The biopsy specimens were examined for acid-fast bacilli by routine histological methods and by fluorescent microscopy. Characteristic histological changes of tuberculosis were reponted in every biopsy specimen.

In 10 of the 30 specimens acid-fast bacilli were seen microscopically in either the histological preparations or the bacteriological smears. In two instances only formalin specimens had been sent to the laboratory, so that culture was not possible, but 14 cultures positive for mycobacteria were obtained from the other 28 . Of the 14 myoobacteria which were cultured 13 proved to be human-strain organisms. The other organism was mycobacterium scrofulaceum, which was sensitive only to cycloserine and ethionamide. Ten of the humanstrain mycobacteria were fully sensitive to all antituberculosis drugs tested; one was resistant only to streptomycin, one only to isoniazid, and one only to para-aminosalicylic acid (PAS).

\section{Treatment and Results}

Though the 32 patients were finally treated at Westminster Hospital seven had had one or more previous episodes treated surgically elsewhere. This and the fact that the patients were treated by a number of different surgeons and physicians account for the variations in the treatment given.

Of the patients who received chemotherapy one was given only streptomycin but the others all had standard treatment with at least two drugs. PAS and isoniazid were used most frequently in the earlier years but later PAS was largely replaced by rifampicin. Ethambutol was the usual choice of 
substitute drug in instances of intolerance to one of the above drugs.

The results of the treatment of the 32 patients from the time their disease first appeared are summarized in fig. 1. Of the seven who initially had surgery without any chemotherapy six relapsed and one died of unrelated disease within three months. The patient who had surgery and streptomycin alone remained well for 14 years but then relapsed. Of the seven whose disease relapsed after surgery without chemotherapy four were again treated by surgery alone and three again relapsed; the other one died of a cerebrovasoular accident 18 months later. Of the three patients who had a further relapse one was yet again treated by surgery without chemotherapy and relapsed for a third time. He was then given chemotherapy and his disease had not recurred 26 months later.

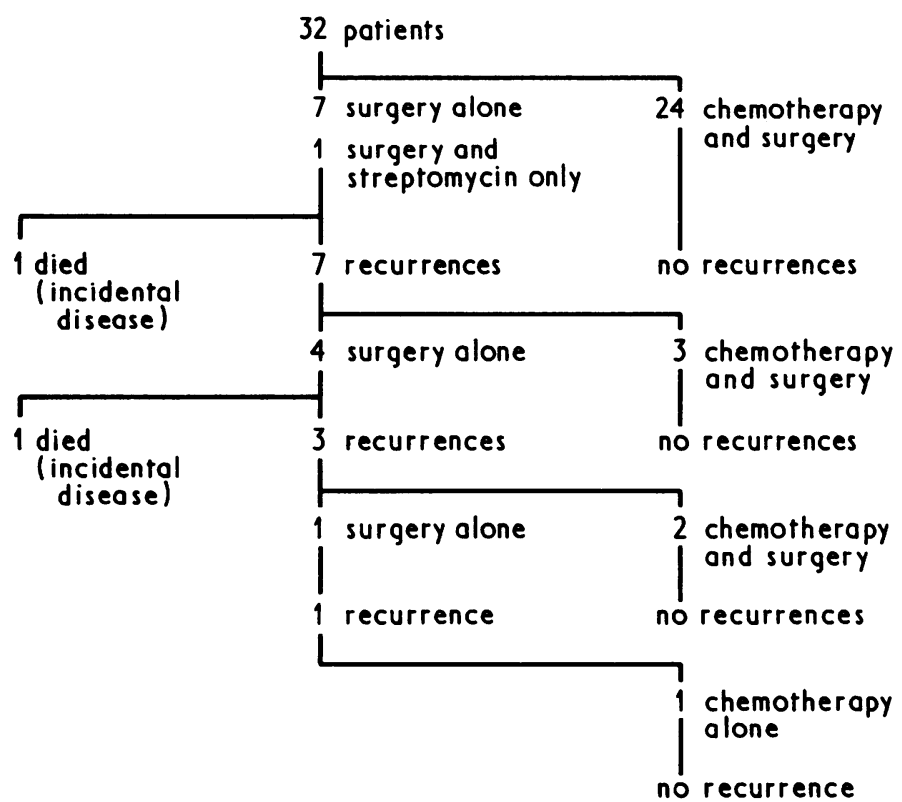

FIG. 1-Flow chart showing results of treatment of the 32 patients from time disease was first treated.

Of the 24 patients who were initially treated by local excision and chemotherapy with at least two drugs none relapsed. After surgical excision plus chemotherapy all remained well for periods of six months to eight years.

The duration of follow-up was longer for the patients treated with surgery alone (mean 10.7 years) than for those who had surgery and chemotherapy (mean 5.5 years). This may partly explain the much worse relapse rate of the surgery only group. We therefore selected those treatment episodes for which the follow-up was at least two years and analysed them in a two- to eight-year follow-up period. The duration of the follow-up and chemotherapy is shown in fig. 2 together with an indication of which patients relapsed; the results are in the table. In the surgery only group the mean follow-up was 6.5 years and five recurrences followed nine episodes of treatment. In the surgery and chemotherapy

Relapse Experience between Second and Eighth Years of Follow-up in the Surgery Only and Surgery and Chemotherapy Groups

\begin{tabular}{l|c|c|c|c}
\hline & $\begin{array}{c}\text { Mean } \\
\text { Follow-up } \\
\text { Time }\end{array}$ & $\begin{array}{c}\text { No. of } \\
\text { Episodes } \\
\text { of Treatment }\end{array}$ & Relapsed & Well \\
\hline $\begin{array}{l}\text { Surgery alone .. .. } \\
\text { Surgery and chemotherapy }\end{array}$ & $\begin{array}{c}6.5 \text { Years } \\
6.2 \text { Years }\end{array}$ & 21 & 5 & 4 \\
\hline
\end{tabular}

$X^{2}=14 ; P<0.001$. group the mean follow-up was $6 \cdot 2$ years and there were no recurrences after 21 episodes of treatment. This result is highly significant $\left(x^{2}=14 ; P>0.001\right)$.

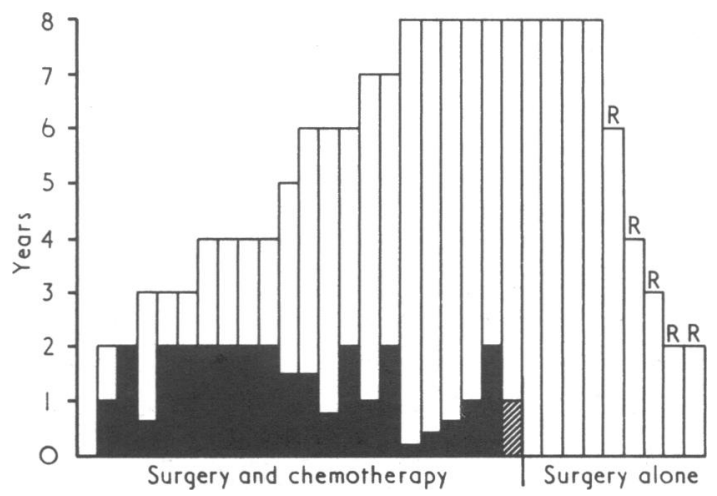

FIG. 2-Duration of follow-up and chemotherapy between second and eighth years. Black areas indicate duration of chemotherapy with two drugs or more. Hatched area indicates use of streptomycin alone. " $R$ " indicates relapse.

\section{Discussion}

The overall results of treatment of tuberculous lymphadenitis in this and other series were unsatisfactory when compared with the results of treatment of pulmonary and other forms of tuberculosis.

The reason why so many of the patients were not given any chemotherapy may have been because most were referred initially to surgeons, who tend not to be so orientated towards the proper initiation and continuation of long-term antituberculosis therapy as are chest physicians. The apparent lack of conviction that chemotherapy is a necessary part of the treatment of tuberculous lymphadenitis must stem pantly from those surgical papers which extolled the virtues of surgical excision alone. (Dowd, 1916; Barrington-Ward, 1937; Peel, 1972).

Our experience has been very different; 12 episodes of tuberculous lymphadenitis treated by surgery alone were followed by 10 relapses. In the two instances in which a relapse was not recorded the patients had died within 18 months from an unrelated cause. These findings are similar to those of Hooper (1972), who found that five out of eight patients treated without chemotherapy relapsed.

The advocates of surgery without chemotherapy assume that tuberculous lymphadenitis is the result of an isolated primary infection of a tonsil or an adenoid or even teeth. Indeed routine tonsilleotomy for children with tuberculous cervical adenitis has been recommended by many authors (Wilmot et al., 1957). Such measures should, however, be unnecessary unless there is overt evidence of septic tonsils or adenoids. In most cases in adults the tonsils are normal and tuberoulous lymphadenopathy is merely a local manifestation of the general disease, and on these grounds alone treatment should be with effective long-term antituberculosis therapy (German et al., 1956; Kent, 1967).

None of the patients in our series who received chemotherapy with two drugs relapsed, but relapse has been reported quite commonly in other series in which antituberculosis chemotherapy was used. Gillam and Knowles (1963) reponted $14(25 \%)$ relapses after six months of antituberculosis therapy; five of the relapses occurred while the drugs were still being given and seven occurred after drugs had been taken for more than 12 months. Fraser (1965) described similat experiences.

A possible cause of failure of chemotherapy could be infection with atypical mycobaoteria or with other drug-resistant 
organisms. Atypical bacteria have been described as a cause of lymphadenitis, particularly in children (Jones and Campbell, 1962; Marsden and Hyde, 1962). In adults, however, the reponted incidence is much less (Krishnaswami et al., 1972). In the present series atypical mycobacterial infection could not be implicated as the cause of drug failure in any of the patients. Similarly, none of the treatment failures in our series could be ascribed to infection with drug-resistant human-type organisms, and this has been an uncommon cause of treatment failure in other reported series.

It seems much more likely that drug treatment of tuberculous lymphadenitis can fail if inadequate tissue levels of antituberculosis drugs are obtained in lymph nodes. This is suggested by the quite common observation that tuberculous lymphadenitis may actually make its first appearance while a patient is having apparently effective antituberculosis therapy for a pulmonary or other lesion. This happened in two of the patients in our series and was also reported by Byrd et al. (1971). Tuberculous lymph nodes may also appear at one site when the patient is already having antituberculosis chemotherapy for diseased lymph nodes elsewhere (Newcombe, 1971).

In our view local excision biopsy should be undertaken to make the diagnosis and obtain material for bacteriological examination, culture, and sensitivity testing. Triple therapy with streptomycin, isoniazid, and rifampicin should be started immediately after operation and continued until the results of the drug sensitivities are known in about six weeks; streptomycin can then, if appropriate, be discontinued. Two-drug chemotherapy should then be continued for two years. In the event of a dubious increase in size of the lymph nodes or the appearance of new ones simply continuing chemotherapy may allow the nodes to subside without further intervention, but if they continue to enlarge or become fluctuant further excision should be carried out.

We wish to thank the physicians and surgeons of Westminster Hospital who have allowed us to study patients under their care.

\section{References}

Barrington-Ward, Sir Lancelot (1937). Lancet, 1, 980

Byrd, R. B., Pnpp, R. K., Gracey, D. R., and Purtiz, E. M. (1971). American Review of Respiratory Diseases, 103, 816.

Dowd, C. N. (1916). Fournal of the American Medical Association, 67, 499.

Fraser, H. S. (1965). British Fournal of Diseases of the Chest, 59, 164

German, J. L., Black, T. C., and Chapman, J. (1956). Diseases of the Chest, $30,326$.

Gillam, P. M., and Knowles, J. P. (1963). Tubercle, 44, 112

Gillam, P. M., and Knowles, J. P. (1963). Tubercle, 44, 112.

Hooper, A. A. (1972). British fournal of Surgery, 59, 353.

Jones, P. G., and Campbell, P. E. (1962). British fournal of Surgery, 50,

Krishnaswami, H., Koshi, G., Kulkani, K. G., and Job, C. K. (1972) Tubercle, 53, 215 .

Marsden, H. B., and Hyde, W. A. (1962). Lancet, 1, 249.

Newcombe, J. F. (1971). Postgraduate Medical fournal, 47, 713.

Peel, A. L. G. (1972). British Fournal of Surgery, 59, 568.

Wilmot, T. J., James, E. F., and Reilly, L. V. (1957). Lancet, 2, 1184.

\title{
Benorylate in Management of Still's Disease
}

\author{
RICHARD H. POWELL, BARBARA M. ANSELL
}

British Medical fournal, 1974, 1, 145-147

\section{Summary}

The present recommended dose of benorylate is not satisfactory for the management of children suffering from inflammatory polyarthritis. A starting dose of $200 \mathrm{mg} / \mathrm{kg} / \mathrm{day}$ should be used, and the salicylate level checked at seven days and the dosage adjusted to give an anti-inflammatory effect-that is, a blood salicylate level of between 25 and $30 \mathrm{mg} / 100 \mathrm{ml}$. Once a satisfactory level has been achieved, this dosage should be maintained with occasional monitoring of the salicylate level. The paracetamol level does not need to be estimated as it tends to follow the salicylate level, provided that liver function is normal; thus it is quite safe to monitor only the salicylate level. Given in an adequate dosage, benorylate seems to be an acceptable salicylate preparation for use in juveniles suffering from chronic polyarthritis.

\section{Introduction}

Benorylate, an ester of aspirin and paracetamol, has been shown to be an effective analgesic anti-inflammatory drug in the treatment of adult rheumatoid arthritis. Beales et al. (1972)

\footnotetext{
M.R.C. Rheumatism Unit, Canadian Red Cross Memorial Hospital, Taplow, Maidenhead, Berks

RICHARD H. POWELL, B.M, B.S., Senior House Officer

BARBARA M. ANSELL, M.D., F.R.C.P., Consultant Rheumatologist
}

found it equivalent to aspirin, with a lower incidence of side effects. It has also been compared favourably with phenylbutazone (Haslock et al., 1971) and indomethacin (Franke and Manz, 1972), and has been shown to cause less gastrointestinal bleeding than aspirin (Croft et al., 1972). A dosage in the order of 100 $\mathrm{mg} / \mathrm{kg}$ is required to obtain an adequate effect.

Chronic polyarthritis in childhood is relatively rare. There are a number of types but the most usual is a form of chronic seronegative polyarthritis usually designated Still's disease in Britain. In the management of such children, despite the introduction of many new drugs, salicylates still remain the treatment of choice (Ansell, 1972).

In general, aspirin preparations are better tolerated by children than by adults, with a much lower incidence of side effects. However, gastrointestinal symptoms and occasionally bleeding can arise. The doses of benorylate currently recommended for children (table I) are based on its analgesic not its anti-inflammatory action and are well below the suggested dosage for adults with rheumatoid arthritis. Because of this it was decided to investigate salicylate and paracetamol levels in children with Still's disease receiving benorylate.

\begin{tabular}{c|c} 
TABLE I-Benorylate Dose Currently Recommended for Children \\
\hline Age & Maximum Recommended Daily Dose \\
\hline 3 months-1 year & $100 \mathrm{mg} / \mathrm{kg}(0.25 \mathrm{ml} / \mathrm{kg})$ \\
$1-2$ years & $1.0 \mathrm{~g}(2.5 \mathrm{ml})$ \\
$3-5$ years & $1.5 \mathrm{~g}(3.75 \mathrm{ml})$ \\
$6-12$ years & $2.0 \mathrm{~g}(5.0 \mathrm{~m} !)$ \\
\hline
\end{tabular}

\section{Method}

The children under study were all inpatients at this hospital 